\title{
Structure and Biochemistry of Cadherins and Catenins
}

\author{
Lawrence Shapiro ${ }^{1}$ and William I. Weis ${ }^{2}$ \\ ${ }^{1}$ Department of Biochemistry and Molecular Biophysics and Edward S. Harkness Eye Institute, Columbia \\ University, New York, New York 10032 \\ ${ }^{2}$ Departments of Structural Biology, Molecular and Cellular Physiology, and Photon Science, Stanford \\ University School of Medicine, Stanford, California 94305 \\ Correspondence: Iss8@columbia.edu
}

Classical cadherins mediate specific adhesion at intercellular adherens junctions. Interactions between cadherin ectodomains from apposed cells mediate cell-cell contact, whereas the intracellular region functionally links cadherins to the underlying cytoskeleton. Structural, biophysical, and biochemical studies have provided important insights into the mechanism and specificity of cell-cell adhesion by classical cadherins and their interplay with the cytoskeleton. Adhesive binding arises through exchange of $\beta$ strands between the first extracellular cadherin domains (EC1) of partner cadherins from adjacent cells. This "strand-swap" binding mode is common to classical and desmosomal cadherins, but sequence alignments suggest that other cadherins will bind differently. The intracellular region of classical cadherins binds to p120 and $\beta$-catenin, and $\beta$-catenin binds to the F-actin binding protein $\alpha$-catenin. Rather than stably bridging $\beta$-catenin to actin, it appears that $\alpha$-catenin actively regulates the actin cytoskeleton at cadherin-based cell-cell contacts.

C adherins constitute a large family of cell surface proteins, many of which participate in $\mathrm{Ca}^{2+}$-dependent cell adhesion that plays a fundamental role in the formation of solid tissues (Takeichi 1995; Tepass 1999; Gumbiner 2005). Many events in the development of multicellular assemblies are associated with changes in cadherin expression (Takeichi 1995; Honjo et al. 2000; Price et al. 2002). Expression of particular cadherins often correlates with formation of discrete tissue structures, and in mature tissues discrete cell layers or other cell assemblies are often demarcated by particular cadherins (Gumbiner 1996). Conversely, down-regulation or loss of cadherins correlates with an increased metastatic potential of the affected cells that arises from the loss of their adhesive properties (Hajra and Fearon 2002; Gumbiner 2005).

The cadherins of vertebrates, and some of their invertebrate homologs, are the most highly characterized. "Classical" cadherins, associated with the adherens junction, and the closely related desmosomal cadherins feature an amino-terminal extracellular region or ectodomain that is followed by a transmembrane anchor and a carboxy-terminal intracellular region. Interactions between ectodomains on

Editors: W. James Nelson and Elaine Fuchs

Additional Perspectives on Cell Junctions available at www.cshperspectives.org

Copyright (C) 2009 Cold Spring Harbor Laboratory Press; all rights reserved; doi: 10.1101/cshperspect.a003053

Cite this article as Cold Spring Harb Perspect Biol 2009;1:a003053 
apposed cells mediate specific cell-cell contacts, whereas the intracellular region functionally links cadherins to the underlying cytoskeleton. This article focuses on structural, biophysical, and biochemical studies that have provided important mechanistic insights into the specificity of cell-cell adhesion and its interplay with the cytoskeleton (see also Meng and Takeichi 2009; Cavey and Lecuit 2009).

\section{Cadherin Function in Specific Cell Adhesion}

Early in vitro experiments with transfected cells demonstrated that cadherin expression can induce cells to aggregate into tissue-like clumps in the presence of $\mathrm{Ca}^{2+}$, suggesting a $\mathrm{Ca}^{2+}$-dependent adhesive function (Takeichi 1977; Takeichi et al. 1981; Takeichi 1988). When cells expressing different cadherin subtypes are mixed, the cells often segregate by cadherin subtype, suggesting that their adhesive function is selective (Takeichi 1990). This "homotypic" cell sorting behavior led to the idea that cadherin molecules of one subtype bind to other molecules of the same subtype but not to cadherins of a different subtype. A classic example occurs during the process of neurulation in vertebrates (Radice et al. 1997). The separation of the neural tube from the embryonic ectoderm layer is mediated in part by expression changes in two cadherins, Eand N-cadherin. Cells of the early ectoderm layer express E-cadherin, and thus adhere together homotypically to form an epithelial cell layer. Some of these cells then "switch" from expression of E-cadherin to expression of $\mathrm{N}$-cadherin. These $\mathrm{N}$-cadherin expressing cells, with their different adhesive properties, are thus displaced from the E-cadherin containing ectoderm to form a new cell layer, which adheres together homotypically via $\mathrm{N}$-cadherin to form the presumptive neural tube (see also Stepniak et al. 2009).

The early notion that cadherin binding preferences are exclusively homophilic is not entirely correct. In vitro experiments that examined sorting of cadherin-transfected cells (Volk et al. 1987; Shimoyama et al. 2000; Duguay et al. 2003; Patel et al. 2006) and binding of such cells to immobilized cadherin ectodomains (Niessen and Gumbiner 2002) revealed substantial crossbinding among different cadherin subtypes, including between $\mathrm{N}$ - and $\mathrm{E}$-cadherins. In addition, heterophilic interactions between the two subgroups of desmosomal cadherins, the desmogleins and desmocollins, have been reported (Chitaev and Tryoanovsky 1997).

Structural studies of cadherin ectodomains have revealed much about the molecular basis of $\mathrm{Ca}^{2+}$-dependent adhesion by cadherins. However, as discussed later, understanding the physical basis for the specificity of tissue patterning by cadherins is still at an early stage.

\section{THE CADHERIN ECTODOMAIN}

\section{Overall Structure of Cadherin Ectodomains}

Cadherin ectodomains are characterized by a repeating amino acid sequence of about 110 residues, each of which corresponds to a protein module of immunoglobulin-like fold called an "extracellular cadherin" or "EC" domain (Overduin et al. 1995; Shapiro et al. 1995a; Nollet et al. 2000; Posy et al. 2008). A loose convention in the literature refers to any protein containing an EC domain as a "cadherin." By this definition, the cadherin superfamily includes structurally diverse proteins including single-pass transmembrane cell adhesion proteins, $\mathrm{G}$ protein coupled receptors, and others, and ranges phylogenetically from single celled organisms to man. Many of these EC domain-containing proteins have poorly characterized function, and the function of the EC domains is unclear. Here, we restrict our focus to cadherins that have been shown to mediate adhesive interactions at the intercellular junction structures they help form between apposed cells. These are the "classical" cadherins and the closely related desmosomal cadherins (Patel et al. 2003; Pokutta and Weis 2007), which mediate adhesion at adherens junctions and desmosomes, respectively.

Classical cadherins, such as E- and Ncadherin, were first identified in vertebrates (Takeichi 1988; Takeichi et al. 1988; Takeichi 1990) and later found to interact with 
cytoplasmic proteins called catenins (Ozawa et al. 1989). Subsequent studies identified EC domain-containing proteins in invertebrates, notably the Drosophila homologs DE- and $\mathrm{DN}$-cadherin that appear to serve tissue patterning functions analogous to their vertebrate counterparts (Oda et al. 1994; Iwai et al. 1997). Although the cytoplasmic regions of $\mathrm{DE}$ - and $\mathrm{DN}$-cadherins are very similar to their vertebrate counterparts, their ectodomains differ markedly, containing up to 15 EC repeats rather than five (Fig. 1). As described later, the mechanistic understanding of ectodomain-mediated adhesion that has been obtained for vertebrate classical cadherins is unlikely to apply to the invertebrate proteins or to other nonclassical members of the cadherin family. The ectodomains of the vertebrate desmosmal cadherins are closely related to classical cadherins, and as discussed below, sequence analysis suggests a similar adhesive mechanism. Desmosomal cadherins differ from classical cadherins in portions of their cytoplasmic regions, which enable their interaction with the intermediate filament system (see Delva et al. 2009).

The vertebrate classical cadherins are subdivided into two closely related families, the type I

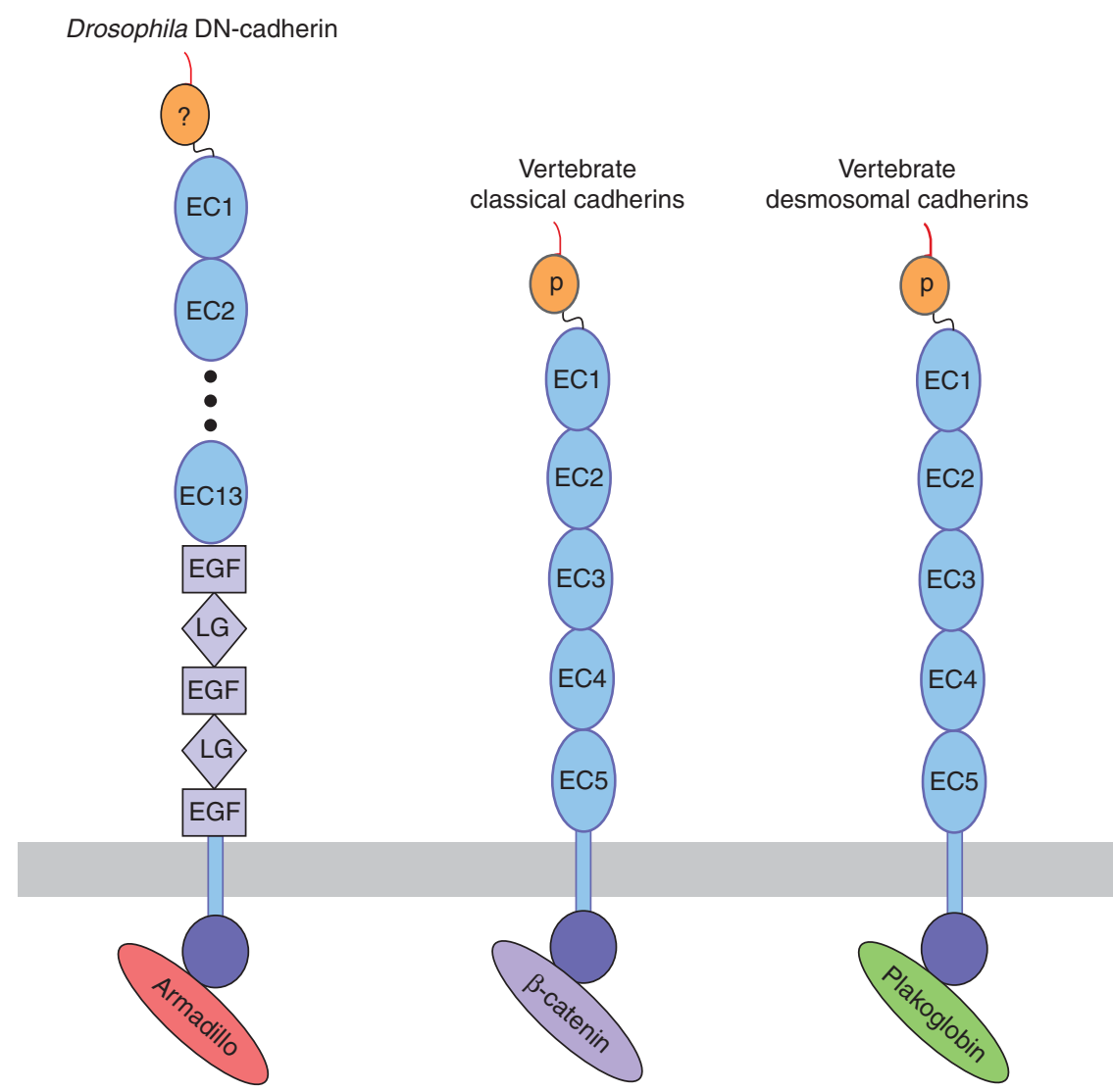

Figure 1. Domain structure of cadherins. The best understood cadherins are the "classical" cadherins of vertebrates, and the closely related desmosomal cadherins. These proteins contain a prodomain $(\mathrm{P})$ immediately following the signal sequence, which is removed by proteolysis. Mature classical and desmosomal cadherins have ectodomains composed of five extracellular cadherin (EC) repeats, a single transmembrane region, and a cytoplasmic domain that interacts with either $\beta$-catenin (classical cadherins) or plakoglobin, also known as $\gamma$-catenin (desmosomal cadherins). Other cadherin family members have widely differing domain structures, as illustrated by the diagram of Drosophila DN-cadherin. 
and type II cadherins. At least 19 classical cadherins are conserved in vertebrate genomes: six type I subfamily members and 13 type II cadherins (Nollet et al. 2000). Type I cadherins typically have broad distributions that are segregated by embryonic germ layer or tissue type (Nishimura et al. 1999). In contrast, type II cadherins show more fine-grained, and often overlapping patterns of expression, notably within the developing nervous system (Bekirov et al. 2002; Price et al. 2002).

\section{Evidence Identifying the Adhesive Binding Sites of Classical Cadherins}

The large majority of data on cadherins suggests that the adhesive binding site is localized to the membrane-distal EC1 domain. The evidence includes domain shuffling experiments in which chimeric cadherins show the specificity of the transplanted EC1 domain (Nose et al. 1990; Shan et al. 1999; Shan et al. 2000), crosslinking with engineered disulfides (Klingelhofer et al. 2002; Troyanovsky et al. 2003; Troyanovsky 2005), and crystallographic (Boggon et al. 2002; Haussinger et al. 2004; Patel et al. 2006; Parisini et al. 2007) and electron tomography (He et al. 2003; Al-Amoudi et al. 2005; Al-Amoudi et al. 2007; Al-Amoudi and Frangakis 2008), structural data described later. However, atomic force microscopy and force spectroscopy experiments have shown that under some conditions, when cadherin-coated surfaces are "pulled apart," force maxima at multiple distances can be observed (Sivasankar et al. 2001; Zhu et al. 2003; Bayas et al. 2006). The multiple steps were interpreted as representing discrete modes of adhesive interaction, with the strongest corresponding to full interdigitation of ectodomains in which EC1 domains would pair with EC5, EC2 with EC4, etc.; the EC1-EC1 interactions were suggested to represent an intermediate, low affinity interaction initially formed before a contact matures (Sivasankar et al. 2001). This discrepancy has caused some controversy in the field, despite the weight of evidence for EC1-EC1 interactions. Recently, a single-molecule fluorescence study by the current Secretary of Energy of the
United States, Steven Chu, appears to have put this controversy to rest. Chu and colleagues labeled the EC1 and EC5 domains of cadherins expressed on cell surfaces with fluorescent dyes, and measured fluorescence resonance energy transfer (FRET) between individual cadherin pairs (Zhang et al. 2009). The results of these studies show that cadherins bind in trans (between cells) by association of their EC1 domains.

\section{High-resolution Cadherin \\ Ectodomain Structures}

Vertebrate classical and desmosomal cadherins are single-pass transmembrane proteins that are encoded as precursor proteins containing a signal sequence and a prodomain that immediately precedes EC1 (Ozawa and Kemler 1990; Patel et al. 2003; Pokutta and Weis 2007). Proteolytic removal of the prodomain by furinlike proteolysis yields the mature ectodomain, comprised of five EC domains repeated in tandem, EC1 to EC5 (Figs. 1 and 2A). The adhesive capacity of classical cadherins depends on removal of the prodomain (Ozawa and Kemler 1990; Haussinger et al. 2004). High-resolution structural studies have been performed on a number of classical cadherin ectodomains and fragments. Each EC domain is composed of seven $\beta$-strands arranged as two opposed $\beta$-sheets with carboxy- and amino-termini at opposite ends, so they can be efficiently repeated in tandem (Overduin et al. 1995a,b; Shapiro et al. 1995a,b). The Greek-key topology of cadherins is identical to that of immunoglobulin constant domains. In keeping with the convention for immunoglobulin superfamily (IgSF) domains, successive strands are labeled A-G, with strands A, G, F, and $\mathrm{C}$ forming one sheet, and strands $\mathrm{D}, \mathrm{E}$, and $\mathrm{B}$ forming the other. The EC1 domains of type I (but not type II) cadherins contain a small loop between the $\mathrm{C}$ and $\mathrm{D}$ strands, designated a "pseudo- $\beta$ helix" in which the backbone torsion angles are $\beta$-like (Patel et al. 2006). This feature is positioned similarly to the C' and C' strands of Ig variable domains. Thus, type I cadherins are remarkably similar to some IgSF 

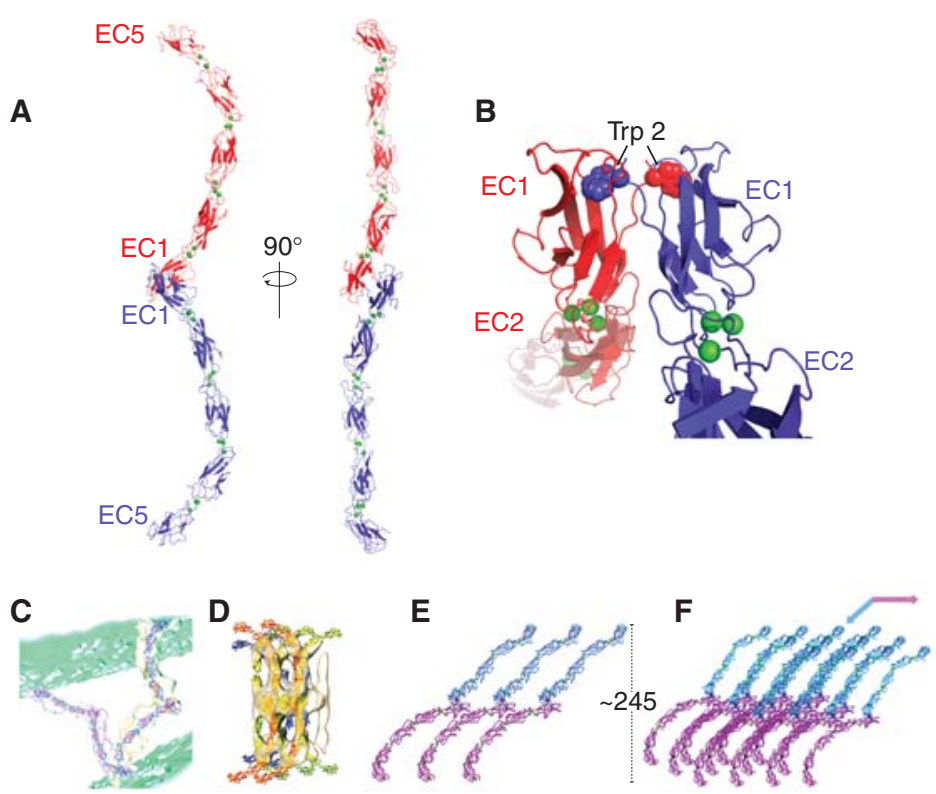

Figure 2. Structures of cadherins. $(A$ and $B)$ Crystal structure of the ectodomain from C-cadherin. $(A)$ Adhesive dimer, joined through the strand-swap interface formed between EC1 domains. (B) Close-up rotated view of the strand-swap interface, highlighting the conserved "anchor" residue Trp 2. Bound calcium ions are shown as green spheres. $(C-F)$ Possible cadherin junction structures. Cryoelectron tomography has been used to acquire three-dimensional images of desmosome junctions in two cases. One of these $(C)$ by $\mathrm{He}$ and colleagues (He et al. 2003) examined plastic-embedded samples and revealed a poorly ordered structure. Another $(D)$ by Al-Amoudi and colleagues (Al-Amoudi et al. 2007) examined frozen hydrated samples and used averaging procedures, and revealed a uniformly repeating structure. Crystals of C-cadherin ( $D$ and $E)$ are arranged in lattice layers suggestive of a junction structure. These structures are made up of intersecting lines of cadherins $(D)$, which together form a two-dimensional array $(E)$.

adhesion proteins that have membrane distal variable-like domains atop a stalk of constantlike domains. Despite this similarity, the hydrophobic cores of cadherin and IgSF proteins are distinct (Shapiro et al. 1995b; Posy et al. 2008), and it is unclear whether cadherins and Ig superfamily adhesion proteins evolved from a common precursor.

Cell adhesion by cadherins depends on the presence of $\mathrm{Ca}^{2+}$. Crystal structures of ectodomain regions containing multiple EC domains show that the connections between successive domains are rigidified by $\mathrm{Ca}^{2+}$ coordination (Nagar et al. 1996; Boggon et al. 2002). Three $\mathrm{Ca}^{2+}$ are coordinated by conserved amino acids contributed from the base of one domain, the top of the next, and the linker region between them (Fig. 2). These $\mathrm{Ca}^{2+}$ binding sites are among the most highly conserved sequence features of cadherins across all species (Nollet et al. 2000; Posy et al. 2008). Structures of the vertebrate proteins show that, in the $\mathrm{Ca}^{2+}$-bound state, successive domains are held at well-defined orientations that impart a strong curvature to the fulllength ectodomain. The curvature of the $\mathrm{Ca}^{2+}$-bound ectodomain, which places the long axes of the EC1 and EC5 domains at a nearly right angle, is evident in the C-cadherin crystal structure (Boggon et al. 2002), electron micrographs of purified E-cadherin ectodomains (Pokutta et al. 1994), and EM tomograms of desmosome junctions between cells ( $\mathrm{He}$ et al. 2003; Al-Amoudi et al. 2007). Removal of $\mathrm{Ca}^{2+}$ leads to a disordering of interdomain orientations, as can be seen by electron microscopy (Pokutta et al. 1994), increased sensitivity to proteolysis, and increased motion between successive domains (Haussinger et al. 2002). 
L. Shapiro and W.I. Weis

\section{The Strand-swapped Adhesive Interface}

Crystallographic studies of type I cadherins have provided detailed information on the nature of the adhesive dimer interface (Shapiro et al. 1995a; Boggon et al. 2002; Haussinger et al. 2004). Its primary feature is the "swapping" of the amino-terminal $\beta$-strands of paired EC1 domains (the A strands) so that the A strand of one monomer replaces the $A$ strand of the other (Fig. 2B). A key element of this twofold symmetric interaction is the insertion of the side chain from the conserved residue Trp- 2 of the A strand of one protomer into a pocket extending into the hydrophobic core of the adhesive partner. Mutations of Trp-2 or its acceptor pocket residues result in the loss of adhesive function for all cadherins tested thus far (Tamura et al. 1998; May et al. 2005). A number of studies have also revealed structures for monomeric cadherins. In some of these structures, the A strand is disordered near Trp-2 (Overduin et al. 1995; Tamura et al. 1998), but in one structure, the side chain of Trp-2 inserts into the core of its own rather than a partner protomer (Pertz et al. 1999).

Exchange of A strands between two partner cadherins is characteristic of the general phenomenon of "3D domain swapping" (Bennett et al. 1995; Liu and Eisenberg 2002; Chen et al. 2005). Consistent with the inherently symmetric nature of this binding mode, the EC1 domains of cadherin pairs presented from apposing cells bind in a parallel fashion even though the overall orientation of the two cadherins is antiparallel (Figs. 2 and 3). The parallel orientation is crucial to achieve a true domainswapped mode of interaction in which nearequivalent interfaces can be achieved in both the monomer and dimer states, and is enabled by the highly curved shape of the cadherin ectodomain.

Crystal structures of type II cadherin ectodomain fragments reveals similar strand-swap binding (Fig. 3). In type II cadherins, Trp-2 plays the same role as it does in type I cadherins but in addition Trp-4, which is conserved in all type II cadherins, also inserts into a hydrophobic pocket of the dimer mate EC1 domain (Patel et al. 2006). Moreover, the EC1-EC1 interface of type II cadherins features a much larger interaction surface arising in part from an extended region of nonpolar contacts that runs along the entire length of the interface. The substantial differences between the binding interfaces of type I and type II
A

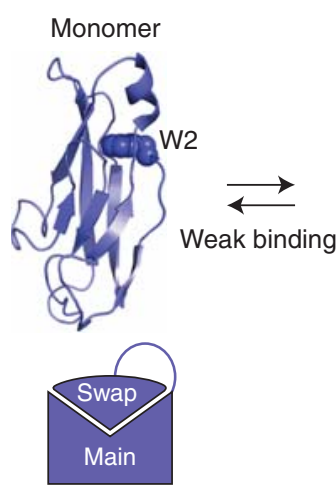

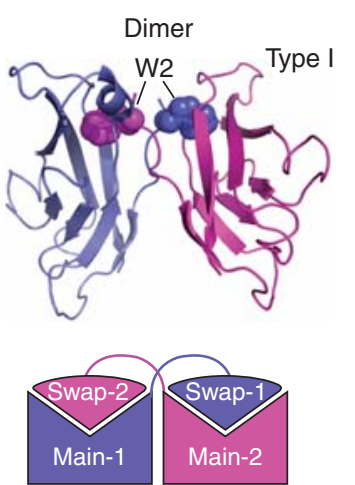

B

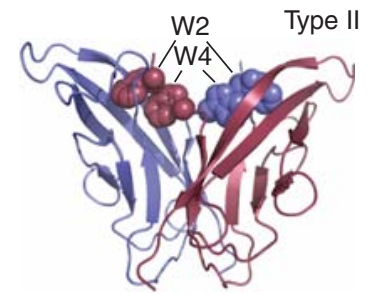

Figure 3. Strand-swap binding by classical cadherins. (A) 3D domain swapping by cadherin EC1 domains. 3D domain swapping provides a simple mechanism for constructing homophilic interfaces. A protein made up of a "main" domain and a "swapping" domain connected by a flexible region can form a "closed" monomer, or a multimer (a dimer in the case of cadherins). These two molecular configurations compete with one another, leading to weak binding affinities. $(B)$ Comparison of strand-swap interfaces of type I and type II classical cadherins. Although folding topology is identical, these two subfamilies have incompatible binding interfaces. Type II cadherins include two conserved Trp anchor residues, rather than one, and form a hydrophobic interface that runs the length of the EC1 domain. 
cadherins provide a simple explanation for the lack of adhesion observed between members of these different subfamilies (Patel et al. 2006). In contrast, the conservation of the central elements of the adhesive interface (for example, the buried Trp side chains) provides a structural explanation for the cross-binding found among members of the same subfamily (Patel et al. 2003). This high level of similarity suggests that, whereas members of different subfamilies will not interact, members of the same subfamily are likely to have graded levels of affinity in cross-adhesion.

Although high-resolution structures have been determined only for classical cadherin ectodomains, sequence analysis strongly suggests that desmosomal cadherins will engage in a similar form of strand-swap binding (Posy et al. 2008). Among the features suggestive of strand-swap binding are a shortened length for the A-strand that engages in strand swapping, and conservation of the anchor residue Trp2 and three residues from the Trp2 binding pocket, Ile24, Tyr36, and Ala80. In contrast, other cadherin families, such as the clustered protocadherins, do not share these features. These observations suggest that desmosomal cadherins, but not others, will engage in strand-swap binding similar to that of classical cadherins.

\section{Unique Properties of Strand-swap Binding}

Although affinity differences lie at the heart of interaction specificity, there have been only a few reports of binding affinities between cadherins, mostly focused on E-cadherin. Surprisingly, a wide range of dissociation constants for dimerization of E-cadherin, ranging from $80-720 \mu \mathrm{M}$ (Koch et al. 1997; Haussinger et al. 2004), have been reported. Structural data provide some insight into the basis of these disparate results. The dimerization interface for classical cadherins, as described above, depends on swapping of the amino-terminal $\beta$-strand. Mutation analysis has shown that the native amino terminus (i.e., that generated by cleavage of the prodomain) is required for cell adhesion, and crystal structures reveal a salt bridge between the amino-terminal amino group and a conserved glutamic acid at position 89 . The salt bridge is also conserved in type II cadherins (Patel et al. 2006). This salt bridge has been shown to play a key role in forming the stand swapped interface (Harrison et al. 2005). However, many of the reported affinity measurements used bacterially produced proteins that contain extensions at their amino-termini. For example, one of these mutant E-cadherins included an extra Met-Arg dipeptide at the amino terminus and gave $K_{D}=170 \mu \mathrm{M}$ (Alattia et al. 1997). On the other hand, a study of a "native" E-cadherin gave extremely weak binding measurements, determined by NMR spectroscopy, with $\mathrm{K}_{\mathrm{D}}=720 \mu \mathrm{M} \quad$ (Haussinger et al. 2004). However, this protein was produced under denaturing conditions with $8 \mathrm{M}$ urea and subsequently refolded, providing a possible explanation for this outlying affinity measurement.

Domain swapping provides a general mechanism of forming homophilic interfaces (Liu and Eisenberg 2002). 3D domain swapping, in general, requires a protomer consisting of a "main" domain and a "swapped" domain, connected by a flexible hinge loop. In this way, symmetric dimers can be formed simply by changing the conformation of the hinge loop. All molecular contacts between "main" and "swapped" domains are locally identical in the dimer and monomer forms, except that they are intramolecular in the monomer, and intermolecular in the dimer. The A strand, containing Trp-2, as shown in Figure 3, constitutes the "swapped" domain for classical cadherins.

Because the A strand can bind to the body of its own protomer, there is competition for dimeric A strand binding (Fig. 3), which lowers the binding affinity (Chen et al. 2005). This reduction of binding affinity via competition with self-binding appears to be common to many domain swapped multimers. In particular, a study of swapped and nonswapped multimers in the PDB showed that binding affinities for assemblies with swapped interfaces were weaker than nonswapped assemblies with similar interfacial buried surface area 
(Chen et al. 2005). It has been proposed that the lowered affinities provided by domain swapping are critical to cadherin specificity in cell adhesion (Chen et al. 2005).

\section{Strand-swap Binding Between Cadherins from Apposed Cells}

Why does the cadherin strand-swap interface preferentially form between cadherins from apposed cells (trans binding), rather than between cadherin molecules from the same cell surface (cis binding)? A substantial body of data has accumulated to suggest that type I cadherins exist as either cis dimers or trans dimers, formed via the same strand-swapped EC1 interface, and that these are mutually exclusive configurations.

Immunoprecipitation studies with differently tagged cadherins show that in the presence of calcium, trans dimers form between apposed cells, whereas cis dimers from cadherins on the same cell predominate in the absence of calcium (Pokutta et al. 1994; Chitaev and Troyanovsky 1998; Shan et al. 2000). Importantly, mutagenesis studies reveal that both cis and trans dimers depend on the strand-swapping interaction (Klingelhofer et al. 2002). Furthermore, sitedirected cross-linking studies (Troyanovsky et al. 2003) show identical cross-link formation for both cis and trans dimers, indicating that they form via the same interface: the strand exchanged dimer of EC1. This behavior can be explained by the rigidification of cadherin ectodomains in the presence of calcium (Pokutta et al. 1994). The geometry of the strand-swap binding interface places orientational constraints on dimer formation. When calcium is present and cadherin ectodomains are rigid, cadherins from apposed cell membranes are oriented so as to easily interact through the strand-swap interface, whereas cadherins from the same cell surface are unable to orient appropriately, hindering cis dimer formation. When calcium is depleted, cadherin ectodomains lose their rigidity and orientation constraints are removed, thus enabling strand-swap dimers to form in cis. Because this cis binding of EC1 domains occurs only in the absence of calcium ions, a condition not encountered in vivo, it seems likely that cis strand-swap binding represents a configuration that has no biological relevance. This is supported by recent single molecule FRET studies, which show that cis dimerization (between cadherins on the same cell surface) is not required for these trans interactions (Zhang et al. 2009).

\section{Assembly of Junctions: Other Potential Lateral (cis) Interactions}

Cadherins assemble between apposed adherent cells into junctional structures (Fig. 2C-F), adherens junctions and desmosomes (Garrod 1986; Geiger et al. 1987). These structures, which have been studied by classical EM and tomography methods (He et al. 2003; AlAmoudi et al. 2007), are densely packed with cadherins, raising the question of whether specific lateral interactions of cadherins on the same cell contribute to the higher-order structure of the junctions. Furthermore, EM studies of liposomes coated with the ectodomain of the type II VE-cadherin reveal junction-like structures (Taveau et al. 2008), suggesting that the ectodomain alone may be sufficient to specify junction structure. These observations have prompted the search for "cis" or lateral interfaces between cadherin ectodomains, but so far, few solid answers have arisen.

The two extant cryo-EM tomography studies of desmosomes (He et al. 2003; AlAmoudi et al. 2007) yield conflicting results on lateral interactions. Although some cis contacts were identified between cadherin ectodomains in both studies, the proposed interaction sites do not agree. The study by Al-Amoudi et al. presents a lattice-like array of cadherins with cis interactions involving a part of the EC1 domain distal from the strandswapping region (Al-Amoudi et al. 2007). In contrast, the desmosome structure determined by Stokes and collaborators is far less ordered, yet shows some cis interactions in the EC5 region (He et al. 2003). These discrepancies likely arise from the different sample preparation techniques used in these studies. Because the resolution in these tomograms is 
low, it is not possible to ascribe specific molecular contacts to these putative cis interactions.

Another potential cis interaction has been identified based on crystal packing interactions in the crystal structure of the EC1-EC5 C-cadherin ectodomain (Boggon et al. 2002). For this interaction, the EC1 domain of one molecule contacts another near the EC2-EC3 linker region. This interaction has also been found in several two-domain structures of E-cadherin (Nagar et al. 1996; Pertz et al. 1999; Boggon et al. 2002; Haussinger et al. 2004), but is absent in structures of Ncadherin (Tamura et al. 1998) and type II cadherins (Patel et al. 2006). In this potential cis interface, the side chain of Asp 44 approaches the $\mathrm{Ca}^{2+}$ binding sites. Mutation of Asp 44 in type I R-cadherin diminishes adhesiveness (Kitagawa et al. 2000), suggesting that these interactions may be relevant. Nevertheless, it is clear that more work needs to be performed to identify and verify potential cis interfaces among classical and desmosomal cadherin ectodomains, and to determine whether such interfaces play a role in junction formation.

\section{Molecular Basis of Cell Adhesive Specificity}

Classical cadherin ectodomains within a subfamily (e.g., Type I cadherins) are remarkably similar. Sequences of the EC1 domains of Eand $\mathrm{N}$-cadherin are 57\% identical, and only a few residues within the strand-swap interface differ. Yet $\mathrm{N}$ - and E-cadherins mediate the homotypic sorting of cells in aggregation experiments (Tamura et al. 1998; Shan et al. 1999). Furthermore, cell sorting specificity resides within the EC1 domain (Nose et al. 1990; Shan et al. 1999). How then can small differences between cadherin EC1 domains determine their cellular specificity? Unfortunately, to date there have been no systematic studies of cadherin binding affinities, so the most important parameters required to address this question remain unknown. Nonetheless, it is clear that multiple interactions can amplify small affinity differences at the molecular level into large differences in intercellular adhesive strength (Chen et al. 2005).
Theoretical frameworks have been proposed to explain how differing cellular affinities can lead to the formation of defined tissue patterns. The "differential adhesion hypothesis" proposed by Malcolm Steinberg in the 1960s posits that mixtures of cells behave like molecules in immiscible liquids, with their sorting properties determined by the adhesion molecules expressed on their surfaces (Steinberg 1962; Steinberg 1975; Steinberg 2007). Thus, cell separations, like that observed for E- and $\mathrm{N}$-cadherin expressing cells, can be thought of as analogous to the separation of oil and water. With the wide range of specificities potentially available to cell adhesion molecules, it is possible that complex tissue patterns could be created by such a mechanism.

\section{THE INTRACELLULAR SIDE OF ADHERENS JUNCTIONS}

Immunoprecipitation of detergent-solubilized cell extracts with anticadherin antibodies identified three major cytoplasmic partners of E-cadherin: $\alpha$-catenin, $\beta$-catenin, and plakoglobin (also known as $\gamma$-catenin) (Ozawa et al. 1989). Subsequent characterization revealed that the cytoplasmic region of $\mathrm{E}-, \mathrm{N}-$, and $\mathrm{P}$-cadherins binds to $\beta$-catenin or plakoglobin, which in turn binds to $\alpha$-catenin (Ozawa et al. 1990; Ozawa and Kemler 1992; Nagafuchi et al. 1991). The high level of sequence identity in the cadherin cytoplasmic region suggests that all classical cadherins interact with the catenins in this fashion. $\alpha$-Catenin has a number of binding partners, including actin (Kobielak and Fuchs 2004). In addition, the protein p120 catenin binds to the juxtamembrane portion of the cadherin cytoplasmic domain (Ozawa and Kemler 1998; Yap et al. 1998; Ohkubo and Ozawa 1999; Thoreson et al. 2000).

Tissues form through cell-cell contacts that are initiated by the cadherin ectodomains, and which strengthen over a time scale of minutes because of rearrangements of the cytoskeleton near the developing junction (Chu et al. 2004). Fluorescence microscopy and time-lapse imaging of developing Madin-Darby canine kidney (MDCK) and keratinocyte epithelium 


\section{Shapiro and W.I. Weis}

has shown that highly dynamic lamellopodial protrusions from opposing cells form initial contacts that contain cell-surface cadherins, $\beta$-catenin, and $\alpha$-catenin (Adams et al. 1996; Adams et al. 1998; Vaezi et al. 2002). Cadherincatenin complexes then cluster into punctate structures spatially coincident with actin filaments that emanate from underlying cortical actin belt (Adams et al. 1996; Adams et al. 1998; Vasioukhin et al. 2000). The subsequent change from lamellopodial contact to a continuously sealed adhesion is driven by reorganization of the actin cytoskeleton. Studies of $\alpha$-catenin-null keratinocytes demonstrate that this process depends on $\alpha$-catenin (Vasioukhin et al. 2000).

In addition to the initial formation of cellcell contacts, tissue remodeling during development requires cells to remain attached to one another while undergoing shape changes that enable morphogenetic movements. Conversely, disassembly of cell-cell contacts occurs during normal development and in metastasis of transformed cells. All of these processes require close coordination of cadherin-mediated adhesive contacts with changes in the underlying cytoskeleton. In the adherens junction, the cytoplasmic complex of cadherins with catenins and elements of the actin cytoskeleton serve this essential role. In this section, we discuss the molecular properties of the cadherincatenin complex and their implications for the regulated assembly of cell-cell contacts.

\section{Cadherin Cytoplasmic Domain}

The cytoplasmic region of classical cadherins, roughly 150 amino acids long, is the most highly conserved portion of these proteins (Nollet et al. 2000). The juxtamembrane region binds to p120, and the carboxy-terminal ca. 100 amino acids bind to $\beta$-catenin and to plakoglobin. Sequences homologous to the $\beta$-catenin/plakoglobin-binding region are also present in the desmosomal cadherins.

The cadherin cytoplasmic domain is unstructured in the absence of a binding partner (Huber et al. 2001), and is an example of an intrinsically unstructured protein (Dyson and Wright 2005; Tompa 2005). Crystal structures of the full 151-residue E-cadherin domain bound to $\beta$-catenin show that the last 100 residues become ordered in the complex (Huber et al. 2001) (Fig. 4). A portion of the

A

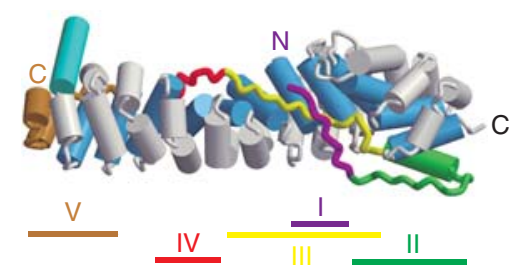

B

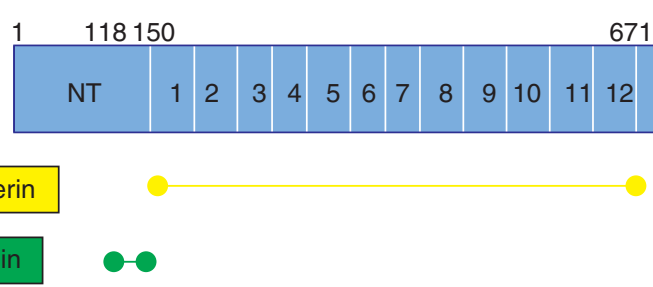

Figure 4. $\beta$-Catenin structure and its complex with E-cadherin cytoplasmic domain. $(A)$ Three-dimensional structure of the $\beta$-catenin arm repeat region in complex with the E-cadherin cytoplasmic domain (Huber and Weis 2001). The arm repeats are formed by three helices, colored gray ( $\mathrm{H} 1$ and $\mathrm{H} 2)$ and blue $(\mathrm{H} 3)$. Residues 134-161, which include the $\alpha$-catenin binding site and a portion of the first arm repeat, form a single helix in this particular crystal structure (cyan). E-cadherin is divided into five regions of primary structure that are indicated in distinct colors. $(B)$ The $\beta$-catenin primary structure. Binding sites for cadherin and $\alpha$-catenin are indicated. 
juxtamembrane cadherin region presumably becomes ordered on forming a stable complex with p120, but this has yet to be verified experimentally.

The lack of structure of E-cadherin in the absence of binding partners may be important to its regulated turnover. Newly synthesized E-cadherin associates with $\beta$-catenin while still in the endoplasmic reticulum, and the two proteins move together to the cell surface (Hinck et al. 1994). Impairing $\beta$-catenin binding leads to proteosomal destruction of cadherin (Chen et al. 1999). The cateninbinding region of cadherins features a "PEST" sequence motif that is recognized by ubiquitin ligases but would be inaccessible in the complex with $\beta$-catenin (Huber et al. 2001; Huber and Weis 2001). Thus, it appears that $\beta$-catenin prevents proteosomal destruction of cadherin, insuring delivery of cadherin$\beta$-catenin complexes to the cell surface.

The interaction of E-cadherin with $\beta$ catenin is very strong and is modulated by phosphorylation (Lickert et al. 2000). In the absence of phosphorylation, the two proteins bind with a $\mathrm{K}_{\mathrm{D}}$ of $36 \mathrm{nM}$ (Choi et al. 2006). Phosphorylation of cadherin by the Ser/Thr kinase CKII increases the affinity to $52 \mathrm{pM}$ (Choi et al. 2006). Mutation of these phosphorylation sites reduces cell adhesiveness (Lickert et al. 2000), but the mechanistic connection between the affinity modulation by phosphorylation and changes in cell adhesiveness is not clear. The phosphorylation increases the on rate and decreases the off rate of the interaction (Choi et al. 2006), and causes more of the PEST region to be structured (Huber and Weis 2001). These observations suggest that one role of phosphorylation could be to further reduce the likelihood that cadherin will be recognized by the cellular destruction machinery.

\section{$\beta$-Catenin}

As part of adherens junctions, $\beta$-catenin binds to the cytoplasmic portion of cadherins and to $\alpha$-catenin. It is also a transcriptional coactivator central to the Wnt signaling pathway that determines cell fate during embryogenesis and tissue renewal in the adult (see Heuberger and Birchmeier 2009; Cadigan and Peifer 2009). Unlike the multitude of cadherins and several tissue-specific $\alpha$-catenin variants, a single $\beta$-catenin protein is present in vertebrates and insects. The protein is highly conserved, with, for example, only six amino acids different between the human and Xenopus proteins, and it is $67 \%$ identical to the Drosophila homolog armadillo. The primary structure of the 781 amino acid $\beta$-catenin consists of an aminoterminal region of about 150 amino acids, a central $\sim 520$ residue domain composed of 12 armadillo (arm) repeats, and a carboxyterminal 100 residue region (Fig. 4B). Ecadherin binds to the arm domain, whereas $\alpha$-catenin binds to residues 118-149, just before the start of the arm domain (Aberle et al. 1996) (Fig. 4B). The arm domain is an elongated superhelical structure formed by the successive packing of helical arm repeats (Huber et al. 1997) (Fig. 4A). The superhelix features a groove that forms part of the binding site for $\beta$-catenin ligands (see Choi et al. 2006 and references therein).

The entire $\beta$-catenin arm domain interacts with cadherin (Fig. 4A). For convenience, we divide the cadherin sequence into five $\beta$-catenin interaction regions. Region I includes a $\beta$ strand that pairs with region III and forms several direct polar contacts with $\beta$-catenin. Cadherin region II includes a helix that interacts with the carboxy-terminal arm repeats. In contrast to the effect of Ser/Thr phosphorylation of cadherin, phosphorylation of $\beta$-catenin Tyr654 (repeat 12) by Src kinase produces a sixfold reduction in affinity (Roura et al. 1999). The phenolic hydroxyl group of the tyrosine side chain forms a hydrogen bond with an aspartate from cadherin (Huber and Weis 2001); phosphorylation would clearly disrupt this interaction. This modification is correlated with a change in cell contacts and the development of a more invasive cell, consistent with dysregulation of the junctional complex, but direct mechanistic data are lacking.

Moving toward the amino terminus of the arm domain, cadherin region III forms an 
extended peptide that binds to the basic groove formed by repeats five and nine (Fig. 4A). This is the site common to Wnt-pathway ligands Tcfs, APC, and the transcription inhibitor ICAT. Region IV is a 10 -residue stretch that contains the target serine residues of CKII and GSK-3 $\beta$. This region binds to repeats three to five only when it is phosphorylated; it is disordered in the structure of the complex of the nonphosphorylated cadherin and the $\beta$-catenin arm domain (Huber and Weis 2001). The extreme carboxyl terminus of cadherin region $\mathrm{V}$ features two small helices that "cap" the amino-terminal arm repeats.

The amino- and carboxy-terminal regions or "tails" of $\beta$-catenin that flank the arm repeats are less well characterized than the arm domain, but their proteolytic sensitivity indicates that these regions are flexibly linked to the arm domain and probably unstructured in the absence of a binding partner. Indeed, these regions are disordered in the crystal structure of full-length $\beta$-catenin (Xing et al. 2008). Although there have been reports that the tails, both of which are acidic, influence ligand binding by competing for binding to the positively charged groove of the arm domain (Piedra et al. 2001; Castaño et al. 2002; Gottardi and Gumbiner 2004), accurate calorimetric affinity measurements showed no significant differences of purified full-length, arm only, $\mathrm{N}+$ arm, or arm $+\mathrm{C} \beta$-catenin constructs binding to E-cadherin, the transcription factor Lef-1, or the transcriptional inhibitor ICAT (Choi et al. 2006). Binding to the lower affinity ligands adenomatous polyposis coli and Axin is influenced by the presence of the amino- and carboxy-terminal tails, but the molecular basis for this effect is not clear (Choi et al. 2006).

The carboxy-terminal tail is highly acidic and functions as a transcriptional activator in Wnt signaling. Analysis of the Drosophila protein indicates that this region is dispensible for adhesion (Cox et al. 1999). In contrast, the amino-terminal tail contains the binding site for $\alpha$-catenin, specifically residues $118-$ 149 , which lie just amino-terminal to the arm domain (Fig. 4B), and is discussed later.

\section{p120 Catenin}

p120 Catenin (p120) is an armadillo-family protein whose arm repeat domain binds to the juxtamembrane region of the cadherin cytoplasmic tail (Daniel and Renynolds 1995; Ohkubo and Ozawa 1999; Thoreson et al. 2000). The arm domain is preceded by an amino-terminal sequence that varies in length in the four splice variants of the protein (Anastasiadis and Reynonds 2000). There appear to be two principal roles for p120. First, it may function to regulate cadherin levels by controlling the rate of cadherin turnover (Ireton et al. 2002; Davis et al. 2003; Xiao et al. 2003; Hoshino et al. 2005; Xiao et al. 2007). Second, p120 controls small GTPases and their effectors that regulate the actin cytoskeleton (Anastasiadis 2007). The interaction with cadherin is thought to localize the small GTPase regulatory activity of p120 at adherens junctions to affect actin organization.

The crystal structure of the arm domain of the desmosomal p120 homolog plakophilin-1 shows that this armadillo protein subfamily contains nine arm repeats; a sequence in the middle of the domain that had predicted to form a 10th repeat is instead a large insertion whose ends form a wedge that introduces a pronounced kink into the domain, making it quite distinct from $\beta$-catenin (Choi and Weis 2005). Nonetheless, the superhelical structure imparted by packing of successive arm repeats gives rise to a prominent groove. By analogy to $\beta$-catenin, the groove may represent the cadherin-binding site, but this has not been verified experimentally.

$\alpha$-Catenin

$\alpha$-Catenin is a roughly 900 -amino-acid protein that is homologous to the focal adhesion protein vinculin. Three isoforms of $\alpha$-catenin have been described, E(epithelial), $\mathrm{N}$ (neuronal), and $\mathrm{T}$ (found in heart and testis). Both $\alpha$-Eand $\alpha-\mathrm{N}$-catenin are coexpressed in a number of tissues, often at different levels and at different developmental stages. Alternative splicing generates two variants of $\alpha-\mathrm{N}$-catenin, the significance of which is unknown. Most of 
the biochemical and structural data reported to date are for $\alpha$-E-catenin. A number of $\alpha$-catenin interaction partners have been reported (Kobielak and Fuchs 2004), but not all have been verified biochemically with pure proteins. Distinct regions of primary structure are associated with binding to different partners (Fig. 5A).

1. Dimerization and $\beta$-catenin binding$\alpha$-E-catenin can homodimerize, but the homodimer dissociates on binding to $\beta$-catenin (Koslov et al. 1997; Pokutta and Weis 2000). The dimerization $/ \beta$-catenin binding region lies near the amino terminus of the protein, in residues 55-264. The crystal structure of the dimerization domain defined by proteolysis, residues $82-264$, starts as a 30-residue $\alpha$ helix, followed by an antiparallel 50-residue helix, then three more helices (Fig. 5B) (Pokutta and Weis 2000). The first half of the long helix pairs with the first helix, and the second half forms part of an antiparallel four-helix bundle at the carboxyl terminus of the domain. The two antiparallel amino-terminal helices pair with the corresponding helices in the other protomer to form an antiparallel four-helix bundle (Fig. 5B).

Alanine scanning mutagenesis demonstrated that $\beta$-catenin residues $118-149$ bind to $\alpha$-catenin largely as an $\alpha$ helix (Aberle et al. 1996). $\alpha$-Catenin residues 57-81, which appear to be flexibly linked to the following dimerization domain, are also predicted to form an $\alpha$ helix (Pokutta and Weis 2000).

\section{A}

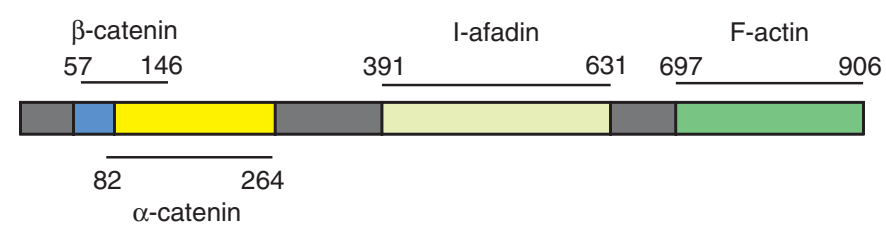

B

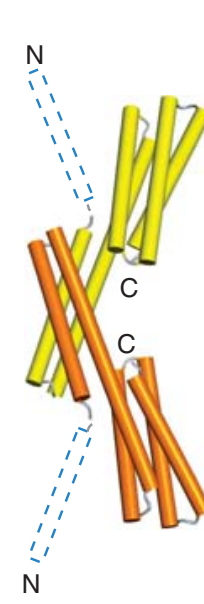

C

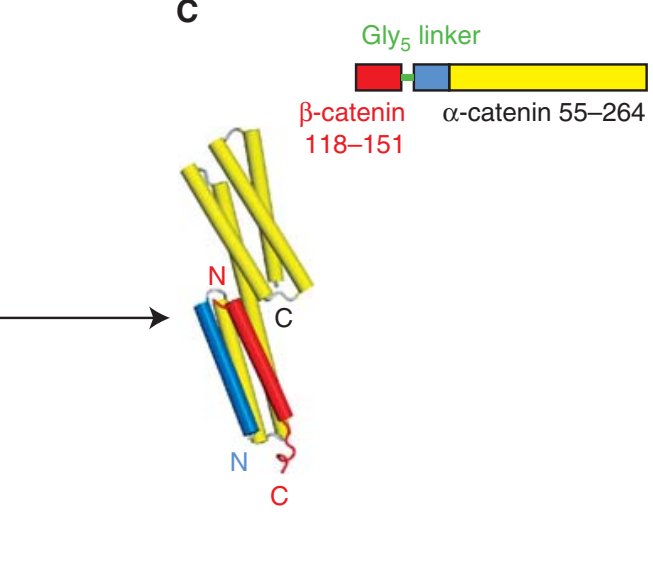

Figure 5. $\alpha$-Catenin structure and $\beta$-catenin binding. (A) The primary structure of $\alpha$-catenin, showing interaction sites mapped by direct binding and/or crystallography. The dimerization domain is shown in yellow; the preceding helix required for $\beta$-catenin binding is shown in blue. The M-domain is shown in light green, and the actin-binding domain in dark green. (B) The three-dimensional structure of the $\alpha$-catenin dimerization region 82-264 (Pokutta and Weis 2000). The protomers of the $\alpha$-catenin dimer are shown in yellow and orange. Residues 57-81, which were not in the crystallized construct and are flexibly linked to the dimerization domain, are schematically illustrated by the dashed blue box. $(C)$ The $\beta \alpha$-catenin chimera primary structure is shown to the right of the crystal structure. The helices of the dimerization region $82-$ 264 are colored in yellow, and the helix formed by $57-81$ in blue. The $\alpha$-catenin binding region of $\beta$-catenin is shown in red. 
These findings suggested a model for the $\alpha$-catenin- $\beta$-catenin interaction in which the $\beta$-catenin residues $118-149$ and $\alpha$-catenin residues 57-79 form two helices that replace one protomer of the $\alpha$-catenin homodimer (Fig. 5B,C) (Pokutta and Weis 2000). To test this model, a chimera in which the $\alpha$-catenin binding site of $\beta$-catenin is fused to residues $57-264$ of $\alpha$-catenin by a flexible linker was constructed to effect a high local concentration of $\beta$-catenin that outcompetes the homodimerization interaction (Pokutta and Weis 2000). The crystal structure of this chimera (Fig. 5C) confirmed the expected overall arrangement of helices. However, the $\beta$-catenin helix and $\alpha$-catenin 57-79 helix pack against the other two $\alpha$-catenin helices at a different angle than those observed in the homodimer. This creates a slightly larger interface, which may account for the observation that when the two proteins are mixed, the $\beta-\alpha$ heterodimer is favored (Koslov et al. 1997). Also, the $\beta$-catenin helix is interrupted at residue 141 , with residues $142-144$ bound in an extended conformation. $\beta$-catenin Tyr142 is buried in the interface. This tyrosine has been found to be a substrate for Met kinase, and phosphorylation of this residue diminishes the $\beta-\alpha$ interaction (Brembeck et al. 2004).

The bulk of endogenous $\alpha$-E-catenin found in MDCK cell extracts is monomeric, but small amounts of both $\alpha$-E-catenin homodimer and $\beta-\alpha$-E-catenin heterodimer are present (Drees et al. 2005). The cytosolic concentration of $\alpha$-E-catenin was estimated to be approximately $0.6 \mu \mathrm{M}$ (Drees et al. 2005). Mixtures of $\alpha$-E-catenin monomer and dimer can be found in purified recombinant material soon after purification when applied to a gel filtration column at a concentration of $2 \mu \mathrm{M}$. These observations suggest that the $K_{D}$ for $\alpha$-catenin homodimer formation lies in the single micromolar range. Gel filtration experiments performed with reasonably pure monomer suggested that the $K_{D}$ for $\beta$-catenin binding is roughly $1 \mu \mathrm{M}$ (Drees et al. 2005), similar to the estimate given from surface plasmon resonance measurements (Koslov et al. 1997).
2. M domain-A second, proteolytically defined region in the middle of $\alpha$-catenin, designated the $\mathrm{M}$ domain, spans residues 377-633 (Yang et al. 2001; Pokutta et al. 2002). This region comprises two four-helix bundles connected by a short linker. Structures of two distinct crystal forms, each containing several crystallographically independent copies, revealed that the relative positions of the two four-helix bundles can vary by as much as 56 (Yang et al. 2001; Pokutta et al. 2002). This interdomain flexibility may be important for transmitting conformational changes between the amino-terminal $\beta$-catenin-binding and carboxy-terminal actin-binding regions, as discussed later.

The $M$ domain is the binding site for l-afadin (Pokutta et al. 2002), an actin-binding protein associated with the Ig-superfamily adhesion molecule nectin (Takai et al. 2008). This adhesion system is thought to be involved in early establishment of cell contacts (Takai et al. 2008). Both $\mathrm{M}$ subdomains are required for the interaction (Pokutta et al. 2002), which may imply that afadin binds to a particular arrangement of the two domains.

3. Actin-binding domain- $\alpha$-Catenin and vinculin bind to filamentous (F-)actin. They differ in that $\alpha$-catenin binds actin constitutively, whereas vinculin is autoinhibited by an interaction between the head and tail regions and therefore requires activation to bind actin. The highest level of sequence homology between these two proteins is found in their carboxy-terminal actin-binding domains (Rimm et al. 1995; Bakolitsa et al. 1999; Pokutta et al. 2002). The vinculin domain is a five-helix bundle (Bakolitsa et al. 1999), and electron microscopy of the vinculin domain bound to F-actin has identified a putative interaction surface (Jannsen et al. 2006). The five-helix architecture and the actin-binding surface residues appear to be conserved in $\alpha$-catenin (Bakolitsa et al. 1999). However, a fragment of $\alpha$-catenin corresponding to the vinculin actin-binding domain does not bind to actin; a 42-amino acid carboxy-terminal extension unique to $\alpha$-catenin is also required, indicating that there are likely to be differences 
in how these two proteins interact with actin (Pokutta et al. 2002).

Comparison of $\alpha$-catenin monomer and dimer binding to actin revealed that the latter binds more strongly to actin (Drees et al. 2005). This is likely an avidity effect because the dimer has two binding sites.

\section{Role of $\alpha$-Catenin in the}

\section{Cadherin-Catenin Complex}

The ability of $\alpha$-catenin to bind to both $\beta$ catenin and F-actin led to the conclusion that $\alpha$-catenin links the cadherin $/ \beta$-catenin complex to actin, providing a stable mechanical linkage between the extracellular contact and the underlying cytoskeleton. However, experiments with purified, recombinant proteins demonstrated that $\beta$-catenin inhibits binding of $\alpha$-catenin to actin (Yamada et al. 2005). The inhibition of $\alpha$-catenin actin-binding activity by $\beta$-catenin was independently confirmed using a different assay (Abe and Takeichi 2008).

Fluorescence recovery after photobleaching experiments performed on fluorescently tagged E-cadherin, $\beta$-catenin, $\alpha$-catenin, and actin showed that the cadherins and catenins have very similar dynamics on the membrane, as expected if they associate as a complex, whereas actin associated with cell-cell contacts diffused more rapidly and was more mobile (Yamada et al. 2005). Deletion of the cadherin cytoplasmic domain or the actin-binding domain of $\alpha$-catenin, either of which would break the putative link between cadherin and actin, did not significantly alter the dynamics of cadherin (Yamada et al. 2005). These results indicate the absence of a stable linkage between the cadherin-catenin complex and actin at cell-cell contacts, consistent with the inhibition of $\alpha$-catenin actin binding activity by $\beta$-catenin. Higher-resolution imaging experiments revealed that in fact there are relatively immobile clusters of E-cadherin and actin in addition to the more dynamic cadherin and actin present at cell-cell contacts, but $\alpha$-catenin is not required for the stability of these clusters (Cavey et al. 2008). In contrast, epithelial architecture appears to be determined by a dynamic actin network that controls the mobility of these adhesive clusters, and this feature requires $\alpha$-catenin. It was suggested that $\alpha$-catenin interacts transiently with actin and $\beta$-catenin to achieve this dynamic architecture, or it does so through interactions with other actin-binding proteins (Cavey et al. 2008).

Several lines of evidence indicate that $\alpha$ catenin regulates actin assembly and dynamics in cell-cell contacts. Reduction of $\alpha$-N-catenin in dendritic spines produces enhanced membrane activity, whereas overexpression results in decreased activity (Abe et al. 2004). Deletion of $\alpha$-E-catenin in keratinocytes results in increased cell migration, a shortened cell cycle, and increased proliferation rather than simple loss of cell-cell adhesion (Vasioukhin et al. 2001; Lien et al. 2006). It is known that the Arp2/3 complex, which nucleates branched actin networks that drive lamellipodial movement needed for cell migration (Pollard and Borisy 2003), interacts with the cadherin complex in nascent cell contacts (Kovacs et al. 2002), and that lamellipodial activity decays as the contacts form (Ehrlich et al. 2002; Vaezi et al. 2002). In vitro actin polymerization experiments demonstrated that $\alpha$-catenin can inhibit the polymerization of actin into branched networks by the Arp $2 / 3$ complex, starting at concentrations of about $1 \mu \mathrm{M}$, above the $\alpha$-catenin concentration of $0.6 \mu \mathrm{M}$ in bulk cytosol (Drees et al. 2005).

These live cell and in vitro observations can be rationalized in a model that explains the change in membrane dynamics and the organization of the actin cytoskeleton during cell contact formation (Fig. 6). Transient contacts between cadherins present on lamellipodia lead to cadherin clustering, which produces a locally high concentration of $\alpha$-catenin at the developing junction. The concentration of $\alpha$-catenin at these sites becomes high enough so that when it dissociates from $\beta$-catenin, it can suppress Arp2/3-stimulated branched actin polymerization, leading to the cessation of lamellipodial movement and formation of a stable cell-cell contact with concomitant reorganization of actin into linear cables 
L. Shapiro and W.I. Weis
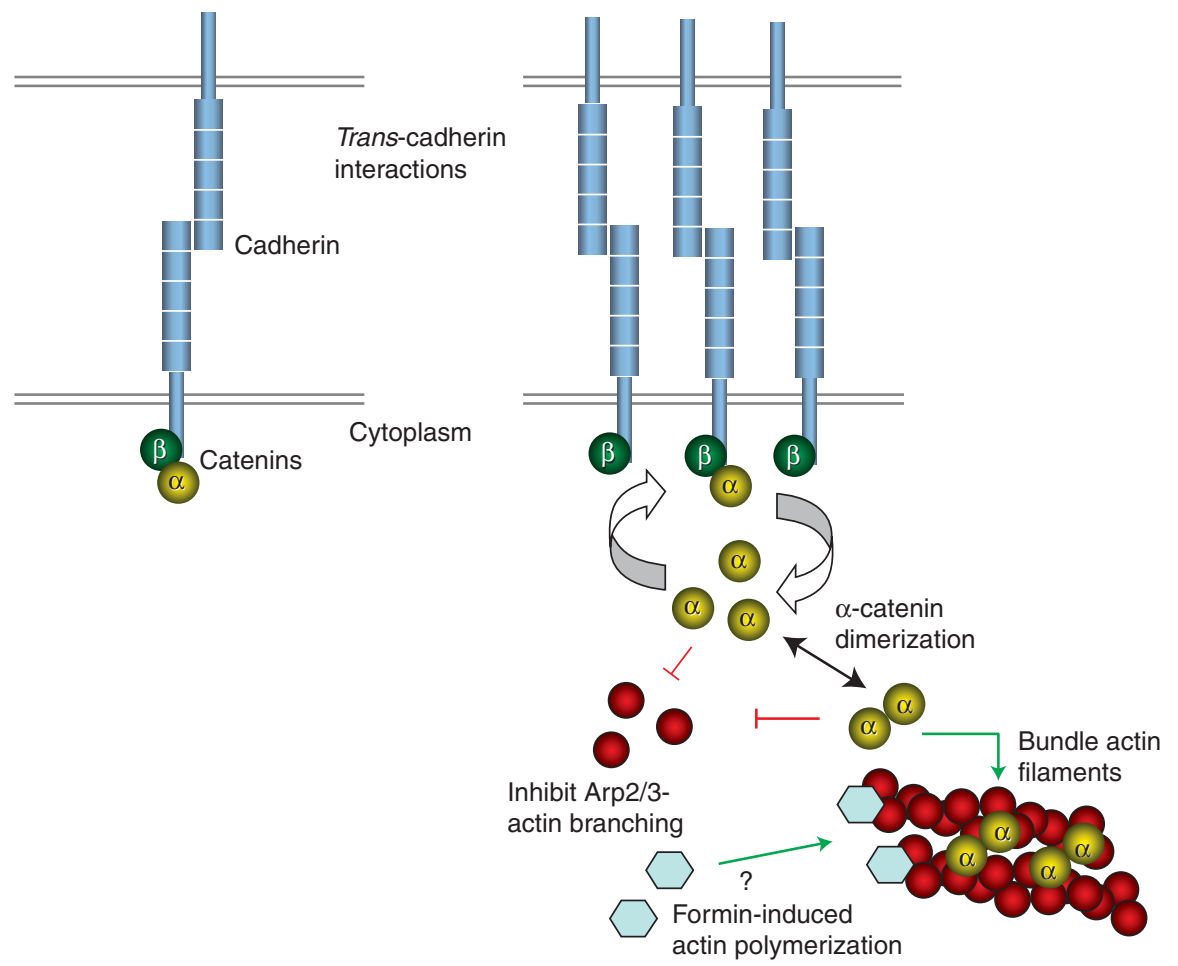

Figure 6. Model of $\alpha$-catenin function in actin polymerization and reorganization in developing cell-cell contacts. See text for details. From Pokutta et al. 2008.

(Drees et al. 2005). The ability of $\alpha$-catenin to bundle actin (Rimm et al. 1995) may indicate that it also has a role in reorganizing actin into the bundles observed in mature contacts. Moreover, it has been reported that formin-1, which promotes formation of linear actin cables, can be positively regulated by $\alpha$-catenin (Kobielak et al. 2004). Thus, $\alpha$-catenin might actively mediate the switch between Arp2/ 3 -stimulated branched actin polymerization and formin-simulated linear actin cable assembly.

As noted previously, Lecuit and colleagues found a portion of actin associated with immobile cadherin clusters, but this association is independent of $\alpha$-catenin. In contrast, $\alpha$-catenin is important for the dynamic architecture of the junctions (Cavey et al. 2008). These authors point out that this "two-tiered" mechanism provides mechanical linkage between adhesion molecules and actin, while allowing dynamic remodeling of the junctions.
Because $\alpha$-catenin does not seem to mediate stable linkage between cadherin and actin, it is likely that other proteins fulfill this role. Although there are candidates (see Weis and Nelson 2006), the components of these immobile clusters are not known. Identifying these molecules will be important to furthering our understanding of adherens junctions and their role in providing mechanical strength to tissues as well as tissue dynamics.

\section{CONCLUSIONS}

Vertebrate classical cadherin ectodomains mediate intercellular adhesion by stereotyped strand-swap binding in their membrane-distal EC1 domains. Differences in the details of the strand-swap interface likely accounts for the lack of binding between type I and type II cadherins. Sequence analysis suggests that desmosomal cadherins will share this binding mode, but other cadherins-including all 
cadherins from invertebrates-likely bind in a different manner.

Clustering of classical cadherin ectodomains play an important role in junction assembly, in part by providing a high local concentration of catenins on the intracellular side of the contact. The chain of binary interactions between cadherin and $\beta$-catenin, between $\beta$-catenin and $\alpha$-catenin, and $\alpha$-catenin and F-actin were thought to indicate that the catenins stably link clustered cadherins to actin, but recent biochemical data indicate that $\alpha$-catenin interactions with actin are negatively regulated by $\beta$-catenin. Instead of serving as a passive linker between the cadherin- $\beta$-catenin complex and actin, it appears that $\alpha$-catenin has an active role in organizing actin near the membrane. The precise role of $\alpha$-catenin and also p120 in organizing and regulating the cytoskeleton at developing and mature contacts remains an important challenge.

\section{ACKNOWLEDGMENTS}

Work in the authors' laboratories is supported by grants GM56169 (W.I.W.) and GM062270 (L.S.) from the National Institutes of Health.

\section{REFERENCES}

Abe K, Takeichi M. 2008. EPLIN mediates linkage of the cadherin-catenin complex to F-actin and stabilizes the circumferential actin belt. Proc Natl Acad Sci 105: 13-19.

Abe K, Chisaka O, Van Roy F, Takeichi M. 2004. Stability of dendritic spines and synaptic contacts is controlled by $\alpha$-N-catenin. Nat Neurosci 7: 357-363.

Aberle H, Schwartz H, Hoschuetzky H, Kemler R. 1996. Single amino acid substitutions in proteins of the armadillo gene family abolish their binding to $\alpha$-catenin. J Biol Chem 271: 1520-1526.

Adams CL, Nelson WJ, Smith SJ. 1996. Quantitative analysis of cadherin-catenin-actin reorganization during development of cell-cell adhesion. J Cell Biol 135: 1899-1911.

Adams CL, Chen Y-T, Smith SJ, Nelson WJ. 1998. Mechanisms of epithelial cell-cell adhesion and cell compaction revealed by high-resolution tracking of E-cadherin-green fluorescent protein. J Cell Biol 142: 1105-1119.

Al-Amoudi A, Frangakis AS. 2008. Structural studies on desmosomes. Biochem Soc Trans 36: 181-187.

Al-Amoudi A, Dubochet J, Norlen L. 2005. Nanostructure of the epidermal extracellular space as observed by cryo-electron microscopy of vitreous sections of human skin. J Invest Dermatol 124: 764-777.

Al-Amoudi A, Diez DC, Betts MJ, Frangakis AS. 2007. The molecular architecture of cadherins in native epidermal desmosomes. Nature 450: 832-837.

Alattia JR, Ames JB, Porumb T, Tong KI, Heng YM, Ottensmeyer P, Kay CM, Ikura M. 1997. Lateral selfassembly of E-cadherin directed by cooperative calcium binding. FEBS Lett 417: 405-408.

Anastasiadis PZ. 2007. p120-ctn: A nexus for contextual signaling via Rho GTPases. Biochim Biophys Acta 1773: 34-46.

Anastasiadis PZ, Reynonds AB. 2000. The p120 catenin family: Complex roles in adhesion, signaling and cancer. J Cell Sci 113: 1319-1334.

Bakolitsa C, de Pereda JM, Bagshaw CR, Critchley DR, Liddington RC. 1999. Crystal structure of the vinculin tail suggests a pathway for activation. Cell 99: 603-613.

Bayas MV, Leung A, Evans E, Leckband D. 2006. Lifetime measurements reveal kinetic differences between homophilic cadherin bonds. Biophys J 90: 1385-1395.

Bekirov IH, Needleman LA, Zhang W, Benson DL. 2002. Identification and localization of multiple classic cadherins in developing rat limbic system. Neuroscience 115: 213-227.

Bennett MJ, Schlunegger MP, Eisenberg D. 1995.3D domain swapping: A mechanism for oligomer assembly. Protein Sci 4: 2455-2468.

Boggon T, Murray J, Chappuis-Flament S, Wong E, Gumbiner B, Shapiro L. 2002. C-cadherin ectodomain structure and implications for cell adhesion mechanisms. Science 296: 1308-1313.

Brembeck FH, Schwarz-Romond Tl., Bakkers J, Wilhelm S, Hammerschmidt M, Birchmeier W. 2004. Essential role of BCL9-2 in the switch between $\beta$-catenin's adhesive and transcriptional functions. Genes Dev 18: 2225-2230.

Castaño J, Raurell I, Piedra JA, Miravet S, Duñach M, García de Herreros A. 2002. $\beta$-Catenin $N$ - and C-terminal tails modulate the coordinated binding of adherens junction proteins to $\beta$-catenin. J Biol Chem 277: 31541-31550.

Cavey M, Lecuit T. 2009. Molecular bases of cell-cell junctions stability and dynamics. Cold Spring Harb Perspect Biol 1: a002998.

Cavey M, Rauzi M, Lenne PF, Lecuit T. 2008. A two-tiered mechanism for stabilization and immobilization of E-cadherin. Nature 453: 751-756.

Chen Y-T, Stewart DB, Nelson WJ. 1999. Coupling assembly of the E-cadherin/b-catenin complex to efficient endoplasmic reticulum exit and basal-lateral membrane targeting of E-cadherin in polarized MDCK cells. J Cell Biol 144: 687-699.

Chen CP, Posy S, Ben-Shaul A, Shapiro L, Honig BH. 2005. Specificity of cell-cell adhesion by classical cadherins: Critical role for low-affinity dimerization through $\beta$-strand swapping. Proc Natl Acad Sci 102: 8531-8536.

Chitaev NA, Troyanovsky SM. 1997. Direct $\mathrm{Ca}^{2+}$. dependent heterophilic interaction between desmosomal cadherins, desmoglein and desmocollin, contributes to cell-cell adhesion. J Cell Biol 138: 193-201. 


\section{Shapiro and W.I. Weis}

Chitaev NA, Averbakh AZ, Troyanovsky RB, Troyanovsky SM. 1998. Molecular organization of the desmogleinplakoglobin complex. J Cell Sci 111: 1941-1949.

Choi H-J, Weis WI. 2005. Structure of the armadillo repeat domain of plakophilin 1. J Mol Biol 346: 367-376.

Choi H-J, Huber AH, Weis WI. 2006. Thermodynamics of $\beta$-catenin-ligand interactions. The roles of the $\mathrm{N}$ - and C-terminal tails in modulating binding affinity. $J$ Biol Chem 281: 1027-1038.

Chu YS, Thomas WA, Eder O, Pincet F, Perez E, Thiery JP, Dufour S. 2004. Force measurements in E-cadherinmediated cell doublets reveal rapid adhesion strengthened by actin cytoskeleton remodeling through Rac and Cdc42. J Cell Biol 167: 1183-1194.

Cox RT, Pai LM, Kirkpatrick C, Stein J, Peifer M. 1999. Roles of the C-terminus of armadillo in Wingless signaling in Drosophila. Genetics 153: 319-332.

Daniel JM, Renynolds AB. 1995. The tyrosine kinase substrate $\mathrm{p} 120^{\text {cas }}$ binds directly to E-cadherin but not to the Adenomatous Polyposis Coli protein or $\alpha$-catenin. Mol Cell Biol 15: 4819-4824.

Davis MA, Ireton RC, Reynolds AB. 2003. A core function for p120-catenin in cadherin turnover. J Cell Biol 163: 525-534.

Delva E, Tucker DK, Kowalczyk AP. 2009. The desmosome. Cold Spring Harb Perspect Biol 1: a002543.

Drees F, Pokutta S, Yamada S, Nelson WJ, Weis WI. 2005 $\alpha$-Catenin is a molecular switch that binds E-cadherin/ $\beta$-catenin and regulates actin filament assembly. Cell 123: 903-915.

Duguay D, Foty RA, Steinberg MS. 2003. Cadherinmediated cell adhesion and tissue segregation: Qualitative and quantitative determinants. Dev Biol 253: 309-323.

Dyson HJ, Wright PE. 2005. Intrinsically unstructured proteins and their functions. Nat Rev Mol Cell Biol 6: 197-208.

Ehrlich JS, Hansen MD, Nelson WJ. 2002. Spatio-temporal regulation of Racl localization and lamellipodia dynamics during epithelial cell-cell adhesion. Dev Cell 3: $259-270$.

Garrod DR. 1986. Desmosomes, cell adhesion molecules and the adhesive properties of cells in tissues. J Cell Sci Suppl 4: 221-237.

Geiger B, Volk T, Volberg T, Bendori R. 1987. Molecular interactions in adherens-type contacts. J Cell Sci Suppl 8: $251-272$

Gottardi CJ, Gumbiner BM. 2004. Distinct molecular forms of $\beta$-catenin are targeted to adhesive or transcriptional complexes. J Cell Biol 167: 339-349.

Gumbiner BM. 1996. Cell adhesion: The molecular basis of tissue architecture and morphogenesis. Cell 84: 345-357.

Gumbiner BM. 2005. Regulation of cadherin-mediated adhesion in morphogenesis. Nat Rev Mol Cell Biol 6: $622-634$.

Hajra KM, Fearon ER. 2002. Cadherin and catenin alterations in human cancer. Genes Chromosomes Cancer 34: 255-268.

Harrison O, Corps E, Kilshaw P. 2005. Cadherin adhesion depends on a salt bridge at the N-terminus. J Cell Sci 118: $4123-4130$.
Haussinger D, Ahrens T, Aberle T, Engel J, Stetefeld J, Grzesiek S. 2004. Proteolytic E-cadherin activation followed by solution NMR and X-ray crystallography. EMBO J 23: 1699-1708.

Haussinger D, Ahrens T, Sass H, Pertz O, Engel J, Grzesiek S. 2002. Calcium-dependent homoassociation of E-cadherin by NMR spectroscopy: Changes in mobility, conformation and mapping of contact regions. $J \mathrm{Mol}$ Biol 324: 823-839.

He W, Cowin P, Stokes DL. 2003. Untangling desmosomal knots with electron tomography. Science 302: 109-113.

Hinck L, Nathke IS, Papkoff J, Nelson WJ. 1994. Dynamics of cadherin/catenin complex formation: Novel protein interactions and pathways of complex assembly. J Cell Biol 125: 1327-1340.

Honjo M, Tanihara H, Suzuki S, Tanaka T, Honda Y, Takeichi M. 2000. Differential expression of cadherin adhesion receptors in neural retina of the postnatal mouse. Invest Ophthalmol Vis Sci 41: 546-551.

Hoshino T, Sakisaka T, Baba T, Yamada T, Kimura T, Takai Y. 2005. Regulation of E-cadherin endocytosis by nectin through afadin, Rap1, and p120ctn. J Biol Chem 280: 24095-24103.

Huber AH, Weis WI. 2001. The structure of the $\beta$-catenin/ E-cadherin complex and the molecular basis of diverse ligand recognition by $\beta$-catenin. Cell 105: 391-402.

Huber AH, Nelson WJ, Weis WI. 1997. Three-dimensional structure of the armadillo repeat region of $\beta$-catenin. Cell 90: 871-882.

Huber AH, Stewart DB, Laurents DV, Nelson WJ, Weis WI. 2001. The cadherin cytoplasmic domain is unstructured in the absence of $\beta$-catenin: A possible mechanism for regulating cadherin turnover. J Biol Chem 276: 12301-12309.

Ireton RC, Davis MA, van Hengel J, Mariner DJ, Barnes K, Thoreson MA, Anastasiadis PZ, Matrisian L, Bundy LM, Sealy L et al. 2002. A novel role for p120 catenin in E-cadherin function. J Cell Biol 159: 465-476.

Iwai Y, Usui T, Hirano S, Steward R, Takeichi M, Uemura T. 1997. Axon patterning requires DN-cadherin, a novel neuronal adhesion receptor, in the Drosophila embryonic CNS. Neuron 19: 77-89.

Jannsen ME, Kim E, Liu H, Fujimoto LM, Bobkov AA, Volkmann N, Hanein D. 2006. Three-dimensional structure of vinculin bound to actin filaments. Mol Cell 21: 271-281.

Kitagawa M, Natori M, Murase S, Hirano S, Taketani S, Suzuki S. 2000. Mutation analysis of cadherin-4 reveals amino acid residues of EC1 important for the structure and function. Biochem Biophys Res Commun 271: $358-363$.

Klingelhofer J, Laur OY, Troyanovsky RB, Troyanovsky SM. 2002. Dynamic interplay between adhesive and lateral E-cadherin dimers. Mol Cell Biol 22: 7449-7458.

Kobielak A, Fuchs E. 2004. $\alpha$-catenin: At the junction of intercellular adhesion and actin dynamics. Nat Rev Mol Cell Biol 5: 614-625.

Kobielak A, Pasolli HA, Fuchs E. 2004. Mammalian formin-1 participates in adherens junctions and polymerization of linear actin cables. Nat Cell Biol 6: $21-30$. 
Koch AW, Pokutta S, Lustig A, Engel J. 1997. Calcium binding and homoassociation of E-cadherin domains. Biochemistry 36: 7697-7705.

Koslov ER, Maupin P, Pradhan D, Morrow JS, Rimm DL. 1997. $\alpha$-catenin can form asymmetric homodimeric complexes and/or heterodimeric complexes with B-catenin. J Biol Chem 272: 27301-27306.

Kovacs EM, Goodwin M, Ali RG, Paterson AD, Yap AS. 2002. Cadherin-directed actin assembly: E-cadherin physically associates with the Arp $2 / 3$ complex to direct actin assembly in nascent adhesive contacts. Curr Biol 12: 379-382.

Lickert H, Bauer A, Kemler R, Stappert J. 2000. Casein Kinase II phosphorylation of E-cadherin Increases E-cadherin $/ \beta$-catenin interaction and strengthens cellcell adhesion. J Biol Chem 275: 5090-5095.

Lien WH, Klezovitch O, Fernandez TE, Delrow J, Vasioukhin V. 2006. a-E-catenin controls cerebral cortical size by regulating the hedgehog signaling pathway. Science 311: 1609-1612.

Liu Y, Eisenberg D. 2002. 3D domain swapping: As domains continue to swap. Protein Sci 11: 1285-1299.

May C, Doody JF, Abdullah R, Balderes P, Xu X, Chen CP, Zhu Z, Shapiro L, Kussie P, Hicklin DJ et al. 2005. Identification of a transiently exposed VE-cadherin epitope that allows for specific targeting of an antibody to the tumor neovasculature. Blood 105: 4337-4344.

Meng W, Takeichi M. 2009. Adherens junction: Molecular architecture and regulation. Cold Spring Harb Perspect Biol 1: a002899.

Nagafuchi A, Takeichi M, Tsukita S. 1991. The $102 \mathrm{kD}$ cadherin-associated protein: Similarity to vinculin and posttranscriptional regulation of expression. Cell 65: $849-857$.

Nagar B, Overduin M, Ikura M, Rini JM. 1996. Structural basis of calcium-induced E-cadherin rigidification and dimerization. Nature 380: 360-364.

Niessen CM, Gumbiner BM. 2002. Cadherin-mediated cell sorting not determined by binding or adhesion specificity. J Cell Biol 156: 389-399.

Nishimura EK, Yoshida H, Kunisada T, Nishikawa SI. 1999. Regulation of E- and P-cadherin expression correlated with melanocyte migration and diversification. Dev Biol 215: $155-166$.

Nollet F, Kools P, van Roy F. 2000. Phylogenetic analysis of the cadherin superfamily allows identification of six major subfamilies besides several solitary members. J Mol Biol 299: 551-572.

Nose A, Tsuji K, Takeichi M. 1990. Localization of specificity determining sites in cadherin cell adhesion molecules. Cell 61: 147-155.

Oda T, Kanai Y, Oyama K, Yoshiura K, Shimoyama Y, Birchmeier W, Sugimura T, Hirohashi S. 1994. E-cadherin gene mutations in human gastric carcinoma cell lines. Proc Natl Acad Sci 91: 1858-1862.

Ohkubo T, Ozawa M. 1999. p120 ctn binds to the membraneproximal region of the E-cadherin cytoplasmic domain and is involved in modulation of adhesion activity. J Biol Chem 274: 21409-21415.

Overduin M, Harvey TS, Bagby S, Tong KI, Yau P, Takeichi M, Ikura M. 1995. Solution structure of the epithelial cadherin domain responsible for selective cell adhesion. Science 267: 386-389.

Ozawa M, Kemler R. 1992. Molecular organization of the uvomorulin-catenin complex. J Cell Biol 116: 989-996.

Ozawa M, Kemler R. 1990. Correct proteolytic cleavage is required for the cell adhesion function of uvomorulin. J Cell Biol 111: 1645-1650.

Ozawa M, Kemler R. 1998. Altered cell adhesion activity by pervanadate due to the dissociation of a-catenin from the E-cadherin catenin complex. J Biol Chem 273: 6166-6170.

Ozawa M, Baribault H, Kemler R. 1989. The cytoplasmic domain of the cell adhesion molecule uvomorulin associates with three independent proteins structurally related in different species. EMBO J 8: 1711-1717.

Ozawa M, Ringwald M, Kemler R. 1990. Uvomorulincatenin complex formation is regulated by a specific domain in the cytoplasmic region of the cell adhesion molecule. Proc Natl Acad Sci 87: 4246-4250.

Parisini E, Higgins JM, Liu JH, Brenner MB, Wang JH. 2007. The Crystal Structure of Human E-cadherin Domains 1 and 2, and Comparison with other Cadherins in the Context of Adhesion Mechanism. J Mol Biol 373: 401-411.

Patel SD, Chen CP, Bahna F, Honig B, Shapiro L. 2003. Cadherin-mediated cell-cell adhesion: Sticking together as a family. Curr Opin Struct Biol 13: 690-698.

Patel SD, Ciatto C, Chen CP, Bahna F, Rajebhosale M, Arkus N, Schieren I, Jessell TM, Honig B, Price SR, et al. 2006. Type II cadherin ectodomain structures: Implications for classical cadherin specificity. Cell 124: 1255-1268.

Pertz O, Bozic D, Koch AW, Fauser C, Brancaccio A, Engel J. 1999. A new crystal structure, $\mathrm{Ca}^{2+}$ dependence and mutational analysis reveal molecular details of E-cadherin homoassociation. EMBO J 18: 1738-1747.

Piedra J, Martínez D, Castaño J, Miravet S, Duñach M, García de Herreros A. 2001. Regulation of $\beta$-catenin structure and activity by tyrosine phosphorylation. $J$ Biol Chem 276: 20436-20443.

Pokutta S, Weis WI. 2000. Structure of the dimerization and $\beta$-catenin binding region of $\alpha$-catenin. Mol Cell 5: 533-543.

Pokutta S, Weis WI. 2007. Structure and mechanism of cadherins and catenins in cell-cell contacts. Annu Rev Cell Dev Biol 23: 237-261.

Pokutta S, Drees F, Yamada S, Nelson WJ, Weis WI. 2008. Biochemical and structural analysis of alpha-catenin in cell-cell contacts. Biochem Soc Trans 36: 141-147.

Pokutta S, Drees F, Takai Y, Nelson WJ, Weis WI. 2002. Biochemical and structural definition of the 1-afadinand actin-binding sites of $\alpha$-catenin. J Biol Chem 277: $18868-18874$.

Pokutta S, Herrenknecht K, Kemler R, Engel J. 1994. Conformational changes of the recombinant extracellular domain of E-cadherin upon calcium binding. Eur $J$ Biochem 223: 1019-1026.

Pollard TD, Borisy GG. 2003. Cellular motility driven by assembly and disassembly of actin filaments. Cell 112: $453-465$.

Posy S, Shapiro L, Honig B. 2008. Sequence and structural determinants of strand swapping in cadherin domains: 


\section{Shapiro and W.I. Weis}

Do all cadherins bind through the same adhesive interface? J Mol Biol 378: 954-968.

Price SR, De Marco Garcia NV, Ranscht B, Jessell TM 2002. Regulation of motor neuron pool sorting by differential expression of type II cadherins. Cell 109: 205-216.

Radice GL, Rayburn H, Matsunami H, Knudsen KA Takeichi M, Hynes RO. 1997. Developmental defects in mouse embryos lacking N-cadherin. Dev Biol 181: 64-78.

Rimm DL, Koslov ER, Kebriaei P, Cianci CD, Morrow JS 1995. $\alpha_{1}(\mathrm{E})$-catenin is an actin-binding and -bundling protein mediating the attachment of F-actin to the membrane adhesion complex. Proc Natl Acad Sci 92: 8813-8817.

Roura S, Miravet S, Piedra J, García de Herreros A, Dunach M. 1999. Regulation of E-cadherin/catenin association by tyrosine phosphorylation. J Biol Chem 274: 36734-36740.

Shan WS, Koch A, Murray J, Colman DR, Shapiro L. 1999. The adhesive binding site of cadherins revisited. Biophys Chem 82: 157-163.

Shan W, Tanaka H, Phillips G, Arndt K, Yoshida M, Colman D, Shapiro L. 2000. Functional cis-heterodimers of Nand R-cadherins. J Cell Biol 148: 579-590.

Shapiro L, Fannon AM, Kwong PD, Thompson A, Lehmann MS, Grubel G, Legrand J-F, Als-Nielsen J, Colman DR, Hendrickson WA. 1995a. Structural basis of cell-cell adhesion by cadherins. Nature 374: 327-337.

Shapiro L, Kwong PD, Fannon AM, Colman DR, Hendrickson WA. 1995b. Considerations on the folding topology and evolutionary origin of cadherin domains. Proc Natl Acad Sci USA 92: 6793-6797.

Shimoyama Y, Tsujimoto G, Kitajima M, Natori M. 2000 Identification of three human type-II classic cadherins and frequent heterophilic interactions between different subclasses of type-II classic cadherins. Biochem J 349: 159-167.

Sivasankar S, Gumbiner B, Leckband D. 2001. Direct measurements of multiple adhesive alignments and unbinding trajectories between cadherin extracellular domains. Biophys J 80: 1758-1768.

Steinberg MS. 1962. On the Mechanism of Tissue Reconstruction by Dissociated Cells, Iii. Free Energy Relations and the Reorganization of Fused, Heteronomic Tissue Fragments. Proc Natl Acad Sci 48: 1769-1776.

Steinberg MS. 1975. Adhesion-guided multicellular assembly: A commentary upon the postulates, real and imagined, of the differential adhesion hypothesis, with special attention to computer simulations of cell sorting. J Theor Biol 55: 431-443.

Steinberg MS. 2007. Differential adhesion in morphogenesis: A modern view. Curr Opin Genet Dev 17: 281-286.

Stepniak E, Radice GL, Vasioukhin V. 2009. Adhesive and signaling functions of cadherins and catenins in vertebrate development. Cold Spring Harb Perspect Biol 1: a002949.

Takai Y, Ikeda W, Ogita H, Rikitake Y. 2008. The immunoglobulin-like cell adhesion molecule nectin and its associated protein afadin. Annu Rev Cell Dev Biol 24: 309-342.
Takeichi M. 1977. Functional correlation between cell adhesive properties and some cell surface proteins. $J$ Cell Biol 75: 464-474.

Takeichi M. 1988. The cadherins: Cell-cell adhesion molecules controlling animal morphogenesis. Development 102: 639-655.

Takeichi M. 1990. Cadherins: A molecular family important in selective cell-cell adhesion. Annu Rev Biochem 59: 237-252.

Takeichi M, Hatta K, Nose A, Nagafuchi A. 1998. Identification of a gene family of cadherin cell adhesion molecules. Cell Differ Dev 25: 91-94.

Takeichi M. 1995. Morphogenetic roles of classic cadherins. Curr Opin Cell Biol 7: 619-627.

Takeichi M, Atsumi T, Yoshida C, Uno K, Okada TS. 1981. Selective adhesion of embyonal carcinoma cells and differentiated cells by $\mathrm{Ca}^{2+}$-dependent sites. Dev Biol 87: $340-350$.

Tamura K, Shan W, Hendrickson W, Colman D, Shapiro L. 1998. Structure-function analysis of cell adhesion by neural (N-) cadherin. Neuron 20: 1153-1163.

Taveau JC, Dubois M, Le Bihan O, Trepout S, Almagro S, Hewat E, Durmort C, Heyraud S, Gulino-Debrac D, Lambert O. 2008. Structure of artificial and natural VE-cadherin-based adherens junctions. Biochemical Society transactions 36: 189-193.

Tepass U. 1999. Genetic analysis of cadherin function in animal morphogenesis. Curr Opin Cell Biol 11: 540-548.

Thoreson MA, Anastasiadis PZ, Daniel JM, Ireton RC, Wheelock MJ, Johnson KR, Hummingbird DK, Reynolds AB. 2000. Selective uncoupling of $\mathrm{p} 120^{\mathrm{ctn}}$ from E-cadherin disrupts strong adhesion. J Cell Biol 148: $189-201$.

Tompa P. 2005. The interplay between structure and function in intrinsically unstructured proteins. FEBS Lett 579: $3346-3354$.

Troyanovsky S. 2005. Cadherin dimers in cell-cell adhesion. Eur J Cell Biol 84: 225-233.

Troyanovsky R, Sokolov E, Troyanovsky S. 2003. Adhesive and lateral E-cadherin dimers are mediated by the same interface. Mol Cell Biol 23: 7965-7972.

Vaezi A, Bauer C, Vasioukhin V, Fuchs E. 2002. Actin cable dynamics and Rho/Rock orchestrate a polarized cytoskeletal architecture in the early steps of assembling a stratified epithelium. Dev Cell 3: 367-381.

Vasioukhin V, Bauer C, Begenstein L, Wise B, Fuchs E. 2001. Hyperproliferation and defects in epithelial polarity upon conditional ablation of $\alpha$-catenin in skin. Cell 104: 605-617.

Vasioukhin V, Bauer C, Yin M, Fuchs E. 2000. Directed actin polymerization is the driving force for epithelial cell-cell adhesion. Cell 100: 209-219.

Volk T, Cohen O, Geiger B. 1987. Formation of heterotypic adherens-type junctions between L-CAM-containing liver cells and A-CAM-containing lens cells. Cell 50: 987-994.

Weis WI, Nelson WJ. 2006. Re-solving the cadherincatenin-actin conundrum. $J$ Biol Chem 281: 35593-35597.

Xiao K, Allison DF, Buckley KM, Kottke MD, Vincent PA, Faundez V, Kowalczyk AP. 2003. Cellular levels of p120 


\section{Cadherin and Catenin Mechanisms}

catenin function as a set point for cadherin expression levels in microvascular endothelial cells. J Cell Biol 163: 535-545.

Xiao K, Oas RG, Chiasson CM, Kowalczyk AP. 2007. Role of p120-catenin in cadherin trafficking. Biochim Biophys Acta 1773: 8-16.

Xing Y, Takemaru K, Liu J, Berndt JD, Zheng JJ, Moon RT, Xu W. 2008. Crystal structure of a full-length $\beta$-catenin. Structure 16: 478-487.

Yamada S, Pokutta S, Drees F, Weis WI, Nelson WJ. 2005. Deconstructing the cadherin-catenin-actin complex. Cell 123: 889-901.

Yang J, Dokurno P, Tonks NK, Barford D. 2001. Crystal structure of the M-fragment of $\alpha$-catenin:
Implications for modulation of cell adhesion. EMBO $J$ 20: 3645-3656.

Yap AS, Niessen CM, Gumbiner BM. 1998. The juxtamembrane region of the cadherin cytoplasmic tail supports lateral clustering, adhesive strengthening, and interaction with p120 ${ }^{\text {ctn }}$. J Cell Biol 141: 779-789.

Zhang Y, Sivasankar S, Nelson WJ, Chu S. 2009. Resolving cadherin interactions and binding cooperativity at the single-molecule level. Proc Natl Acad Sci 106: 109-114.

Zhu B, Chappuis-Flament S, Wong E, Jensen IE, Gumbiner BM, Leckband D. 2003. Functional analysis of the structural basis of homophilic cadherin adhesion. Biophys $J$ 84: 4033-4042. 


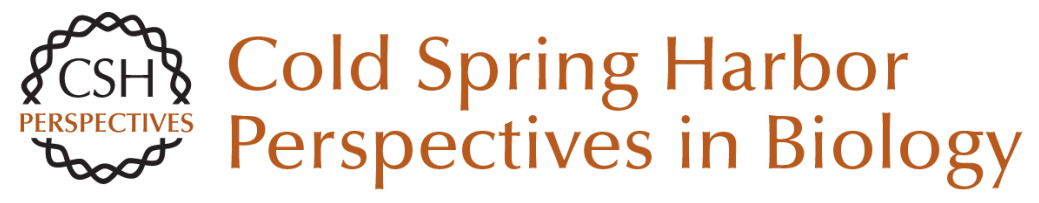

\section{Structure and Biochemistry of Cadherins and Catenins}

Lawrence Shapiro and William I. Weis

Cold Spring Harb Perspect Biol 2009; doi: 10.1101/cshperspect.a003053 originally published online August 19, 2009

\section{Subject Collection Cell-Cell Junctions}

Vascular Endothelial (VE)-Cadherin, Endothelial Adherens Junctions, and Vascular Disease Maria Grazia Lampugnani, Elisabetta Dejana and Costanza Giampietro

Adherens Junctions and Desmosomes Coordinate Mechanics and Signaling to Orchestrate Tissue Morphogenesis and Function: An Evolutionary Perspective Matthias Rübsam, Joshua A. Broussard, Sara A. Wickström, et al.

Cell-Cell Contact and Receptor Tyrosine Kinase Signaling Christine Chiasson-MacKenzie and Andrea I. McClatchey

Hold Me, but Not Too Tight---Endothelial Cell-Cell Junctions in Angiogenesis Anna Szymborska and Holger Gerhardt

\section{Connexins and Disease}

Mario Delmar, Dale W. Laird, Christian C. Naus, et al.

\section{Cell Junctions in Hippo Signaling}

Ruchan Karaman and Georg Halder

Loss of E-Cadherin-Dependent Cell-Cell Adhesion and the Development and Progression of Cancer Heather C. Bruner and Patrick W.B. Derksen
Signaling by Small GTPases at Cell-Cell Junctions: Protein Interactions Building Control and Networks

Vania Braga

Making Connections: Guidance Cues and Receptors at Nonneural Cell-Cell Junctions lan V. Beamish, Lindsay Hinck and Timothy E. Kennedy

The Cadherin Superfamily in Neural Circuit Assembly James $D$. Jontes

Mechanosensing and Mechanotransduction at Cell-Cell Junctions Alpha S. Yap, Kinga Duszyc and Virgile Viasnoff

Beyond Cell-Cell Adhesion: Sensational

Cadherins for Hearing and Balance Avinash Jaiganesh, Yoshie Narui, Raul Araya-Secchi, et al.

Cell-Cell Junctions Organize Structural and Signaling Networks Miguel A. Garcia, W. James Nelson and Natalie Chavez

Cell Biology of Tight Junction Barrier Regulation and Mucosal Disease Aaron Buckley and Jerrold R. Turner

For additional articles in this collection, see http://cshperspectives.cshlp.org/cgi/collection/

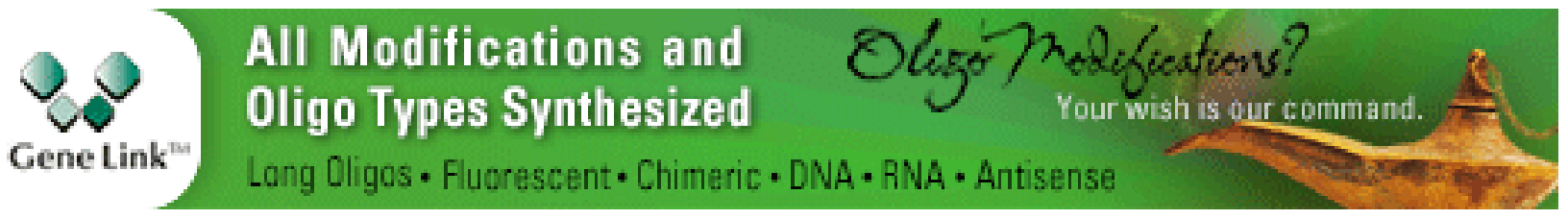


Desmosomes and Intermediate Filaments: Their Consequences for Tissue Mechanics Mechthild Hatzfeld, René Keil and Thomas M. Magin
Integration of Cadherin Adhesion and

Cytoskeleton at Adherens Junctions

René Marc Mège and Noboru Ishiyama

For additional articles in this collection, see http://cshperspectives.cshlp.org/cgi/collection/

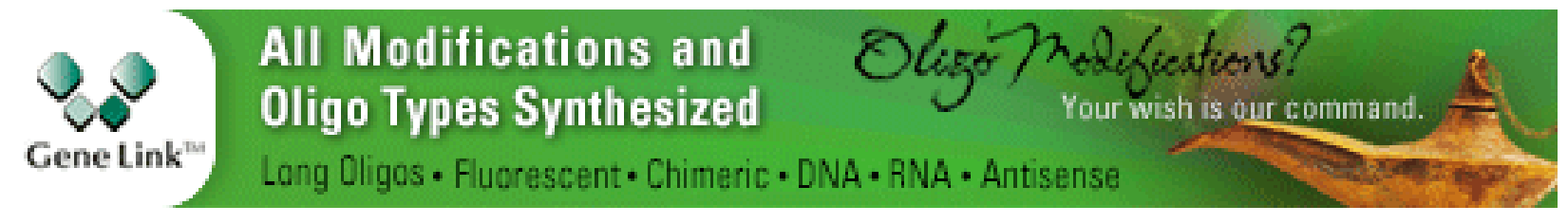

Copyright @ 2009 Cold Spring Harbor Laboratory Press; all rights reserved 